\title{
A Study on Translation and Dissemination Channels of Shaanxi Literary Works to the World from the Perspective of Communication
}

\author{
Sun Feiran \\ Xi'an Fanyi University, Xi'an 710105, China
}

Key Words: translation; dissemination; Shaanxi literature; channels; Communication

\begin{abstract}
The Going-Global Campaign of Shaanxi literary works is deemed as an important way to introduce Shaanxi culture to the rest of the world so as to improve its image and strengthen the influence of Shaanxi on the world. Since translation, an important medium for cultural exchange and ideological communication, plays an important role in the dissemination of Shaanxi literature,this paper, based on the present situation of Shaanxi literature, attempts to discover the problems in the process of translation and dissemination, explore the channels of "going out" of Shaanxi literature from the perspective of Communication and then put forward some constructive opinions.
\end{abstract}

\section{Introduction}

The Going-Global Campaign of Chinese culture, a national strategy which has been implemented in recent years in China, is of great significance to enhance the soft power of national culture and promote the cultural exchangesbetween China and the rest of world. As an important part of Chinese culture, literature is an important way for people all over the world to understand Chinese history, culture and tradition. However, the dissemination of Chinese literature in the Western world has been facing various difficulties, especially the translation and dissemination of Shaanxi literature. As a province honored for its local literature, Shaanxi has a long history of cultural heritage and works which carry the local tradition. In order to makethese works known to and leave a comprehensive picture of Shaanxito the world, the role of translation cannot be ignored. Therefore, in the context of the new era, the translation and introduction of Shaanxi literature is worth pondering.

\section{The Current Situation of the Translation and Dissemination}

Shaanxi is well-known for its abundant literary works. Writers like Liu Qing, Lu Yao, Chen Zhongshi, Jia Pingwa with their excellent literary works can be said to be a household name. In terms of the translation of these works,Entrepreneurial History by Liu Qingwas firstly translated.In 1964, the Japanese version of the novel was published inJapan.Then, its English version waslaunchedinChina mainlandin 1977. In 1990, Lu Yao's Life was also translated and published domestically. The earliest English translationof Chen Zhongshi'snovelsis Trust, included in Mao's harvest: a new generation of Chinese voice(1983). TheJapanese and French version of the novel White Deer was published respectively in 1996 and2012. In the same yearof 2012, the short story Story from the Twelfth Lunar Month was included in the collection Sword of the Water and Otherand then published in the U.S.A. The Japanese version of the novel Cai Sangzi written by a female writer, Ye Guangqin, was published in 2002. In addition, the most representative ofthe 
translation of Shaanxi literary works is Jia Pingwa'sbooks. To some extent, the translationand introduction of his works intoother countries represent the current situation of the dissemination of Shaanxi literature. In fact, since the 1970s, the English versions of Jia's works, such as Qi Qiao'er, Duan Yang, etc., have been published inChinese Literature. Then, the 1980s witnessed his works translated into various languages and published in foreign countries, which had a profound influence on the international literature community. One of the influential works is Turbulence, translated by the Sinologist Ge Haowen, winning “Mobil Pegasus Prize for Literature”in America. This book was also collected by 547 libraries around the world.

However, as totoday's Shaanxi literary translation, it can be concluded as "more said, lessdone”. Actually, there are only three books translated by local people: one is Jia Pingwa's novel Darkytranslated by $\mathrm{Hu}$ Zongfeng and published in the American classical literary journal "New Literature" in 2011, covering one third of the pages in the first period; the second is Ye Guangqin'sQing Mu Chuan translated by the Secretary-General of Shaanxi Translation Association, Gao Minna, and other translators; the last one is a translated collection of short storiesTwenty Shaanxi WritersbyShaanxi Translation Association. Obviously, compared with the output of literary works, its local translation works are relatively scarce.

\section{Problems of Shaanxi Literary Translation and Dissemination and Its Reasons}

Throughout the history of Shaanxi literature, although achievements have beenmadein the translation of works, there are still many difficulties. First of all, the amount of the translatedworks is insufficient, mostlybeing famous writers' works while other excellent literary works have been ignored. Secondly, among the translations of the famous works, the proportion these writers account for is obviously imbalanced. Jia Pingwa's works are translated much more than Lu Yao's and Chen Zhongshi's. Moreover, the English versions of Shaanxi works are quite scarce; for example, till now, there are still no far-reaching versions of Jia Pingwa's representative works Missing Wolfand Qin Qiang.Chen Zhongshi's masterpiece White Deeris still not completely translated into the English version, which is a great pity in Shaanxi literary translation.

Based on the above analysis, the reasons for the lack of translations of local works can be concluded as following: First of all, the use of dialectsis a major feature of Shaanxi literary works which increases the difficulty of translation. Translators not only meet the needs of target-language readers, but also preserve the original culture, thus asking for a higher requirement fortranslators. Furthermore, translation is the bridge of the communication between two cultures, andthe acceptance of thereader greatly affects the effectiveness ofdissemination. Second, translators are needed. At present, most of the works are translated by sinologists and there is still no stable system of translation and introduction. In addition, the number of local translators in Shaanxi is extremely scarce; Third, appropriate policies are urgently needed to support the translation work.

\section{The Channels of the Translation and Dissemination of Shaanxi Literature}

Since the implementation of the "Going-Global" Campaign of Chinese culture, the government has made a sequence of policies. In terms of the translation and dissemination of Shaanxi literature, the steady promotion of Shaanxi literature to the world also requires strong support from the government, such as increasing the capital input, facilitating the communication between writers and translators, improving the system of translation, assisting publishing and disseminating, strengthening the supervision and management of publishing, sales and other channels. If necessary, the government can stand out to promote the cooperation. 
The research into and translation of literary translationshould not be confined to the academic community.Peoplewho are interested in literature and translation should not be overlooked. They play a positive role in promoting the "going global" of Shaanxi literature.It is necessary to encourage and guide these devotees of literature at home and abroad to work together, forming a positive force. With the help of the advanced communication techniques, translators can exchange and share experiences.Therefore, the great support and attention should be given to the folk powerwhich is of great benefit to the dissemination of Shaanxi literature

With the rapid development of information and technology, the status of traditional media, such as publishing, newspapers, radio, film and television, has been gradually weakened. New forms of media including online media, mobile phones, digital TV, etc. are flourishing and their advantages are becoming more and more evident. Therefore, the dissemination of literary works must follow the trend of the times, making use of different media channels for communication. Such kind of communication can be individual as well as official. In short, the diversification of literary-work dissemination can provide a good environment of acceptance for the target readers, thereby intensifying the speed of dissemination.

The scarcity of local translators is an indisputable fact. It is far more enough to just rely on sinologists to help Shaanxi literature go out. To meet the needs of a large amount of the translation and dissemination of literary works, it is very urgent to train local translators withhigh standards. It is known that there are only about 30 translators working for the literary translation in Shaanxi, and most of them are the college teachers. Due to the fact that works of translation are not regarded as academic achievements in universities, most of these teachers, just out of their interest in and love for literature, volunteer to be engaged in translation. Therefore, a variety of platforms for translators and lovers are hopefully provided by he governmentor ocal organizations so as to strengthen exchange and cooperation among local translators and between local translators and overseas sinologists, helping them learn from each other and promote the development of Shaanxi literary translation.

\section{Conclusion}

Translation is not only the basis of cross-cultural transmission of literary works, but also an important way for the world to be exposed to Chinese culture. Although the translation of Shaanxi literature has made some achievements, there are still some obstacles to be overcome.Meanwhile, from the perspective of Communication, the channel is an important part of the popularization of Shaanxi literature.Only by constantly exploring new ways of translation and dissemination, can we quicken the "goingout"ofShaanxi literature to the worldand gradually expand the international influence of Shaanxi literature.

\section{Acknowledgements:}

Project: “On the Dissemination of Red Literature \& Art of Xi'an and its English Translation Method Options” supported by 2016 Xi’an Social Science Planning Fund Project (No.16XF04)

\section{Reference}

[1]Bao Xiaoying. The Reception of English Translations of Mo Yan's Oeuvre and the Light it Sheds on the Globalization of Chinese Literature [J]. Chinese Translators Journal, 2015(01): 13-17.

[2] Chen Zhongshi. Bai Lu Yuan[M]. Beijing: People’s Literature Publishing House, 1993.

[3] Helen F. Siu, Zelda Stern Mao’s Harvest:Voices from China`s New Generation, Oxford 
University Press, 1983.

[4] Hua Liang, A Tentative Model of Translation and Dissemination of Chinese Literary Works to the Rest of the World from the Perspective of Mass Communication [J], Journal of Nantong University, 2015(06):70-76.

[5] Jia Pingwa. Old Xi'an :evening glow of an imperial city[M], Beijing: Foreign Language Press, 2001.

[6] Jia Pingwa. Turbulence[M]. Howard Goldblatt, trans. Louisiana: Louisiana University Press,1991.

[7] Liu Qing. Chuang Ye Shi[M]. Beijing: China Youth Publishing Group, 1960.

[8] Qiao Yan, On the Translation and Dissemination of JIA Pingwa' Works- the Current Situation and Problems [J]. Xiao Shuo Ping Lun, 2014(01):75-83.

[9] Sun Li-ang. The Spread and Influence of Shaanxi Literature Overseas -With Jia Pingwa's Works as an Example[J]. Journal of Shangluo University, 2016(03):19-24.

[10] Xia Mingqin. Literary Province Can Not Be Called Province of Translation-Only Three Local Translation Works [EB/OL]. http:// www. sxdaily. com. cn/n/ 2016/0612 /c324-5898769. html. 2016-06-12. 